\title{
Experimental Characterization of Galloping Detonations in Unstable Mixtures
}

Yuan $\mathrm{Gao}^{1}$, Hoi Dick Ng${ }^{2 \dagger}$, John H.S. Lee ${ }^{1}$

${ }^{1}$ Department of Mechanical Engineering,

McGill University, Montréal, Québec, H3A 2K6, Canada

${ }^{2}$ Department of Mechanical and Industrial Engineering, Concordia University, Montréal, Québec, H3G 1M8, Canada

†Corresponding Author

Department of Mechanical and Industrial Engineering

Concordia University

1455 de Maisonneuve Blvd. West

Montréal, Québec, H3G 1M8, Canada

e-mail: hoing@encs.concordia.ca

Tel.: +1 (514) 848-2424 (ext. 3177)

Fax: +1 (514) 848-3175

Revised manuscript submitted to Combustion and Flame

January, 2015 


\begin{abstract}
Some features of galloping detonations near the detonation limits are discussed in this paper. The experimental results previously reported in Gao et al. [Y. Gao, J.H.S. Lee, H.D. Ng, Combust. Flame, 161(11) (2004), 2982-2990], together with additional data obtained in this study for six explosive mixtures with different reaction sensitivities, each in five different diameter tubes, are analyzed in detail. It is established that galloping detonations do not occur in highly argon-diluted, stable mixtures. Only in unstable mixtures, susceptible to flow fluctuations by thermo-chemical instability, when using in small tube diameters (i.e., $D \leq 12.7 \mathrm{~mm}$ ), could galloping detonations be observed. For the largest tube diameter $D=50.8 \mathrm{~mm}$, the detonation wave fails completely when the initial pressure approaches the detonation limit even for all unstable mixtures. In addition, the present study shows that the initial pressure range for the occurrence of galloping detonations decreases rapidly with increasing tube diameter. A collection of existing data on galloping detonations indicates that the wavelength $L$ of one galloping cycle is on average about $350 \mathrm{D}$ within experimental variations. Nonetheless, there appears to be some minor decreasing trend with increasing tube diameter (i.e., $D \geq 12.7 \mathrm{~mm}$ ), or with increasing detonation instability of the explosive mixture. The amplitude of the galloping cycle is also investigated and the upper velocity values show more fluctuations than the lower ones. The upper and lower values of the velocity in the galloping cycle at different conditions vary from $V_{\mathrm{CJ}}$ to $1.5 V_{\mathrm{CJ}}$ and $0.3 V_{\mathrm{CJ}}$ to $0.65 V_{\mathrm{CJ}}$, respectively. To illustrate the role of flow instability on galloping detonations, experiments are performed with a spiral inserted into the 12.7-mm diameter tube to generate perturbations artificially. Detonation waves are observed to re-initiate quickly after passing the spiral and another cycle of galloping detonation was formed in the remaining part of the tube.
\end{abstract}

Keyword: Galloping detonation; Near-limit behaviors; Unstable mixtures 


\section{Introduction}

As the detonation limits are approached, large longitudinal fluctuations of the detonation velocity are often observed [1-5]. Of particular interest is the phenomenon of "galloping detonations" where the detonation decays from an overdriven state to a low-velocity regime, and then re-accelerates back to the overdriven state for the next cycle. The wave velocity can thus vary from about 1.5 to 0.4 of the Chapman-Jouguet velocity $V_{\mathrm{CJ}}$. The length of a single galloping detonation cycle typically spans over hundreds of tube diameters.

Galloping behaviors of detonations were first observed by Mooradian and Gordon [6] in hydrogen-air mixture at the initial pressure of about two atmospheres in a 10-m long, 20-mm diameter tube. Such periodic behavior was also reported by Duff et al. [7], who christened it the so-called "galloping detonation". Manson et al. [8] made a detailed investigation of galloping detonation for propane-oxygen-nitrogen mixtures in tubes of different length $L$ and diameter $D$. From streak Schlieren photographs, they found that the detonation wave decays to a shock wave with a trailing reaction zone, and re-couples again during reacceleration to the overdriven state. St-Cloud et al. [9] investigated in more detail the structure of galloping detonations in propane-oxygen-nitrogen mixtures in a $10 \times 20 \mathrm{~mm}$ tube and found that the reaction zone completely separated from the leading shock during the low velocity phase of the galloping cycle. Subsequently the shock and reaction front re-coupled again in the acceleration to overdriven phase of the galloping cycle.

The continuous monitoring of the velocity during a galloping cycle was made by Edwards and Morgan [10], Lee et al. [2] and Haloua et al. [3] using microwave Doppler interferometry technique. Using a 10-m long and 38.4-mm diameter tube, galloping detonations were observed by Lee et al. [2] in a number of hydrocarbon-oxygen and -air mixtures. Similarly, galloping 
detonations in stoichiometric propane-oxygen mixtures without or with small inert gas dilution were also observed in the later study by Haloua et al. [3] using a longer tube (24.5-m long, 38.4-mm diameter) to obtain at least one complete galloping cycle. These studies found generally that the local velocity during a galloping cycle varies approximately from $0.3 V_{\mathrm{CJ}}$ to $1.5 V_{\mathrm{CJ}}$ and the mean value is about $0.6 V_{\mathrm{CJ}}$. However, with excess amount of inert gas dilution (i.e., argon or helium), galloping detonations were not observed. Similar experimental observations on galloping detonations in various combustible mixtures were also reported in the literature [11-17]. Analytical models of galloping detonations taking into account losses and boundary layer effect have been developed by Ul'yanitskii [18] and Aksamentov et al. [19]. Also, two-dimensional Navier-Stokes simulations of the near-limit propagation of detonation with detailed chemistry were performed recently by Tsuboi et al. [20]. Their numerical smoked foil is shown to reproduce qualitatively the experimentally observed features of galloping detonations [16]. However, all these studies only provide qualitative information on the galloping phenomena.

The phenomenon of detonation limits has been a subject in focus in a number of recent studies. The majority of the studies were concerned with the steady velocity deficits and the operating definition of the detonation limits, e.g., [21-27]. A recent observation of galloping detonation was made by Jackson et al. [4], who recorded up to 18 cycles of galloping in the unstable stoichiometric propane-oxygen mixture using a very long tube $(L / D>10,000)$ of diameter of $4.8 \mathrm{~mm}$. This result confirms that the galloping mode is an unstable phenomenon that can persist for numerous cycles. Susa et al. [28] recently investigated galloping detonation and reported the dependence of the oscillatory characteristics of galloping detonation on the initial pressure and tube diameter. Of particular interest is also the work of Vasil'ev [16], who used smoked foils to observe the structure of galloping detonations and found that the detonation 
decays from multi-headed to single-headed detonation, and finally no cellular structure in low velocity phase of the galloping cycle. In a recent paper [29], we have also reported similar cellular structure evolution of galloping detonation in small diameter tubes. In addition, by reporting the velocity fluctuations near the detonation limits, it also shows that galloping detonations are only observed in particular types of mixture composition and tube diameters [29]. Further interpretation of those reported data, other key parameters such as the effect of initial pressure, the influence of detonation instability of the combustible mixtures, and basic galloping features such as the wavelength and amplitude of the oscillatory cycles have not yet been discussed.

Despite the large number of investigations in the literature, the galloping detonation phenomenon is still not fully understood. It remains unclear under what conditions can galloping detonation be observed. Table 1 provides a summary of all the observations and it appears that galloping detonations are not observed in highly argon-diluted mixtures and in relatively large diameter tubes. It also suggests that unstable mixtures (where detonations have irregular cellular patterns) and small tube diameters are necessary conditions to produce galloping detonations. The mechanisms of propagation of galloping detonations are also not clear. It might be that the detonation decays to a deflagration followed by DDT to re-initiate an overdriven detonation to begin the next galloping cycle. Thus the galloping cycle is one of repeated decay to deflagration and DDT. However, if this is the case then the galloping cycle may not be so reproducible since the turbulent flame acceleration mechanisms leading to DDT are highly random. Alternatively, galloping detonation may be analogous to the pulsating detonations reported in numerous numerical simulations where the oscillatory structure relies on the strong coupling between the gasdynamic processes and chemical reactions; and the acceleration phase of the galloping cycle 
is through the mechanism of shock wave amplification by coherent energy release (SWACER) [1]. This line of thought agrees with the work carried by Ul'yanitski [18], who reported that an analogy can be made for the galloping state with the model for a cell in a multi-front detonation. The numerical simulation by Aksamentov et al. [19] also suggests that galloping detonations are related to one-dimensional detonations with respect to velocity and pressure oscillations.

The aim of the present study is to provide more information on galloping detonations particularly to establish the requirement where galloping detonations can be obtained and the propagation mechanism. To this end, we analyze in detail the results reported previously in [29] and perform additional experiments. In total, three stable mixtures with high argon dilution and three unstable mixtures with highly irregular cell patterns are tested. The tube diameters range from $1.5 \mathrm{~mm}$ to $50.8 \mathrm{~mm}$ since previous studies indicated that small diameter tubes are required to generate galloping detonations. We also determine the length of the galloping cycle, the amplitude of the velocity fluctuations in a galloping cycle, and the range of initial pressure for galloping detonations. New experiments are also carried out to elucidate the prominent role of instability on galloping detonations by using a spiral to generate perturbations artificially.

\section{Experimental setup}

All experiments (both in [29] and in this study) were obtained using the facility shown in Fig. 1. Its full description and the experimental procedure can be found in [27, 29]. Therefore, details are omitted here. In this work, results using an additional mixture not reported in [29] are also presented. More experiments were carried out to extend the local velocity data with smaller initial pressure increments and to investigate the effect of perturbations resulting from the insertion of a spiral (discussed in a later section). For each experiment, the setup was evacuated 
to at least $0.01 \mathrm{kPa}$ and then filled with test mixtures that were premixed beforehand in separate vessels. Experimental data were gathered for three argon-diluted stable mixtures (i.e., $\mathrm{C}_{2} \mathrm{H}_{2}+$ $\left.2.5 \mathrm{O}_{2}+19.8 \mathrm{Ar}(85 \% \mathrm{Ar}), \mathrm{C}_{2} \mathrm{H}_{2}+2.5 \mathrm{O}_{2}+8.2 \mathrm{Ar}(70 \% \mathrm{Ar}), \mathrm{C}_{2} \mathrm{H}_{2}+5 \mathrm{~N}_{2} \mathrm{O}+6 \mathrm{Ar}(50 \% \mathrm{Ar})\right)$ and three unstable mixtures (i.e., $\mathrm{C}_{3} \mathrm{H}_{8}+5 \mathrm{O}_{2}, \mathrm{C}_{2} \mathrm{H}_{2}+5 \mathrm{~N}_{2} \mathrm{O}, \mathrm{CH}_{4}+2 \mathrm{O}_{2}$ ), see $[30,31]$. For stable mixtures with a very large amount of argon dilution, the chemical reactivity is usually less sensitive to any flow perturbation, hence the detonation structure is "piece-wise laminar" and the cellular front is regular. In contrast, the unstable mixtures considered in this study are typically characterized by high activation energies and hence, the chemical reaction is susceptible to flow disturbances. This results in a highly unsteady reaction zone with small-scale fluctuations or instabilities and the cellular detonation pattern in unstable mixtures is highly irregular. In the experiment, detonation was initiated by a high energy spark discharge in a driver section where a short length of Shchelkin spiral was also inserted, and propagated into the transparent polycarbonate tubes at the end of the driver tube. Five different tube diameters, $D=1.5,3.2,12.7$, 31.7 and $50.8 \mathrm{~mm}$, were used with total tube length $l=2438.0,2438.0,4118.0,4118.0,4118.0$ $\mathrm{mm}$, respectively. Equivalently, this gives a $l / D$ of about $1625,762,324,129$ and 81, respectively. Regularly spaced photodiodes (IF-95OC) along the entire length of the test section are used as the main diagnostics to detect the time-of-arrival of the wave for the local velocity measurement. The initial pressure was monitored by an Omega model PX309-030AI pressure transducer (0-30 psi) with an accuracy of $\pm 0.25 \%$ full scale. The digit meter is calibrated to display the minimum pressure reading of $0.01 \mathrm{kPa}$. The lower pressure range is checked with a more accurate digital manometer model HHP242-015A (0 to 15 psi) with an accuracy of $\pm 0.10 \%$ full scale. The pressure measurement should thus have a degree of accuracy $\pm 0.1 \mathrm{kPa}$. For the length scale measurement such as the diameter of the tube, a conservative estimate of its uncertainty is given 
to be $\pm 0.1 \mathrm{~mm}$ (The digital Vernier Caliper has an accuracy of $\pm 0.01-0.02 \mathrm{~mm}$ ). The CJ detonation velocity $V_{\mathrm{CJ}}$ of various mixtures is calculated using the NASA CEA program [32]. For a given mixture and tube diameter, the detonation limits are approached by progressively lowering the initial pressure.

\section{Results and discussion}

\subsection{Effect of mixture type and tube diameter}

Velocity measurements near the detonation limits for different mixtures and tube diameters were presented previously in [29] and obtained in this work for another additional mixture. The conditions under which galloping detonations could be observed are summarized here in a map shown in Fig. 2. No galloping detonation was observed in the highly argon-diluted mixture in all the tubes with diameter $1.5 \mathrm{~mm} \leq D \leq 50.8 \mathrm{~mm}$. From the experimental results, when the limiting pressure is reached, the detonation failed immediately upon entering the tube and no signal from the optical probes registered afterward due to insufficient luminosity. This agrees with the results in the literature provided in Table 1 whereby galloping detonations were only reported in hydrocarbon mixtures without or with small amounts of inert gas dilution, i.e., in explosive mixtures with a high degree of detonation instability. In fact, by diluting the mixture with large amount of argon, it is well-established that instability at the detonation front is suppressed and the cellular patterns are highly regular [30, 31]. Due to the absence of a galloping mode in highly argon-diluted mixtures, it appears that the instability of the tested mixture is one of the factors that can affect the occurrence of galloping detonations.

As found in [29], in the 50.8-mm diameter tube, no galloping detonations were observed 
even in the unstable mixture. As the limiting pressure is approached, the detonation velocity progressively decreases until the light from the detonation front is too weak to be registered. For the results of the 31.7-mm diameter tube (see shaded region in Fig. 2), in several cases, the wave propagation velocity is found to remain fairly constant at about $0.4 V_{\mathrm{CJ}}$ and some slight reacceleration was observed at the end of the tube [29]. Due to the insufficient length of the tube, it remains inconclusive, under these conditions, whether the detonation wave will fail or re-initiate again to develop into a galloping detonation. More experiments with longer tube lengths are therefore required to further distinguish this boundary. From Table 1, the tabulated results obtained from the literature also indicate that the largest tube diameter for the existence of galloping detonation is of about $45 \mathrm{~mm}$ [14] and most galloping detonations are observed in much smaller diameter tubes.

The fact that galloping detonations are only observed in small diameter tubes for unstable mixtures perhaps suggests that it is due to the boundary layer effect. As discussed in the introduction, the galloping cycle includes a relatively long low velocity phase during which the shock is planar without any cell structure and the reaction front trails behind. It is plausible that the boundary layer effect provides a mechanism to keep the reaction front going at about the same speed as the shock as postulated in the paper by Manzahalei [15]. The effect of boundary layer may seem to explain why no galloping detonations are observed in big diameter tubes. Nevertheless, it is important to point out that such a mechanism represents a kinematic effect to make a slow flame (or burning velocity) propagate at a speed fast enough to follow the shock. The model thus provides only an explanation on why the flame moves at the same velocity as the shock. It does not shed any light on the dynamic effect of energy release supporting the shock and leading to the rapid acceleration to an overdriven detonation. In addition, such effect is only 
dominant in capillary tubes when the thickness of the boundary layer is comparable to the small tube diameter. Hence this mechanism cannot fully explain the case of galloping detonations in a diameter tube as big as $31.7 \mathrm{~mm}$ where the boundary layer is thin compared to the diameter.

The key question is thus how energy release by chemical reactions feed to the leading shock front to maintain its speed and subsequently lead to its re-acceleration. Equivalent to one-dimensional pulsating unstable detonation [31,33], temperature-sensitive reaction zones in unstable mixtures can generate longitudinal waves that can travel back and forth to the shock front. The re-acceleration phase of the pulsating cycle is often found numerically from the amplification of a pressure pulse through the shock amplification through coherent energy release (SWACER) mechanism [1,29]. Nevertheless, it is found in numerical simulations that for very high activation energy, as in typical realistic mixtures, a self-sustained pulsating detonation could not be obtained in a purely one-dimensional configuration, i.e., with no dynamics in the transverse direction or tube diameter [31,33]. In other words, for realistic mixtures, the longitudinal instability alone is not sufficient to provide the necessary conditions to maintain the pulsating behavior.

For the low-velocity phase of the galloping cycle, unstable mixtures that are sensitive to flow perturbations are also susceptible to transverse acoustic wave generation in the gas between the shock and the travelling reaction front. The resulting transverse fluctuations can further enhance the reaction rate and supply energy to the shock front, keeping it from decaying. The transverse acoustic waves amplify via reflections from the tube walls and the proper phase relationship with the energy release rate, supporting the re-acceleration phase in the galloping cycle. In contrast, in a stable reaction zone as in highly argon-diluted mixtures, the lack of a chemical instability mechanism to generate and amplify transverse acoustic waves fails to 
support the occurrence of galloping detonations. Some studies also suggest that transverse acoustic vibrations at a sufficiently high frequency get amplified faster, resulting in larger flow fluctuations during the low-velocity phase that stimulates the re-acceleration of the shock-reaction zone complex to an overdriven detonation $[34,35]$. Qualitatively a smaller tube diameter should stimulate a higher frequency of acoustic wave interactions and reflections from the wall to amplify. Although qualitative in nature, the role of transverse acoustic disturbances and their frequency of interaction with the tube wall on the amplification process may give a reasonable account for the absence of galloping detonations for large diameter tubes and argon-diluted stable mixtures.

\subsection{Effect of initial pressure}

In this study other conditions and characteristics featuring galloping detonations are investigated. Experimentally, there exists a range of initial pressure $\Delta P^{*}=P_{\mathrm{U}}-P_{\mathrm{L}}$ (where $P_{\mathrm{U}}$ is the upper bound when galloping detonations first appears and $P_{\mathrm{L}}$ is the lower bound below which galloping detonations do not exist) for the occurrence of galloping detonations. This is analogous

to single headed spinning detonations where they exist over a range of initial pressure. It is of interest to determine $\Delta P^{*}$ and see its dependence on mixture and tube diameters. Figure 3 shows the $P_{\mathrm{U}}$ and $P_{\mathrm{L}}$ for the three unstable mixtures as a function of the tube diameter. In the 1.5-mm diameter tube, the pressure range of $\mathrm{CH}_{4}+2 \mathrm{O}_{2}$ mixture is about $38.0 \mathrm{kPa}$, which is much larger than the other two unstable mixtures. Again, since $\mathrm{CH}_{4}+2 \mathrm{O}_{2}$ is the most unstable mixture and therefore the higher degree of instability of this mixture permits the galloping detonation to exist over a larger span of initial pressure. From this figure, the general trend is that $\Delta P^{*}$ decreases rapidly as the tube diameter increases, and at the largest tube diameter of $D=12.7 \mathrm{~mm}$ where they are still observed, $\Delta P^{*}$ is very narrow (of the order of $1.0 \mathrm{kPa}$ ). From this result, it can be 
deduced that for large diameter tubes $\Delta P^{*} \rightarrow 0$ and hence galloping detonations are not observed.

\subsection{Wavelength and amplitude of the galloping cycle}

Figure 4 shows the periodic nature of the galloping detonation velocity in $\mathrm{CH}_{4}+2 \mathrm{O}_{2}$ in two tube diameters of $D=1.5 \mathrm{~mm}$ and $3.2 \mathrm{~mm}$. For a galloping detonation (treating them as a periodic longitudinal wave), one can determine the wavelength $L$ of the galloping cycle as shown in the figure. The wavelength $L$ is normalized with respect to the tube diameter, i.e., $L / D$. In Fig. 4 a and $4 \mathrm{~b}, L / D$ is 400 and 375 for $D=1.5 \mathrm{~mm}$ and $3.2 \mathrm{~mm}$, respectively. The dependence of $L / D$ on initial pressure $P_{\mathrm{o}}$ for the three unstable mixtures and on tube diameter is illustrated in Fig. 5. There is a fair amount of scatter of $L / D$ but the galloping phenomenon is highly reproducible across experiments. For each mixture and tube diameter, the $L / D$ dependence on the narrow range of initial pressure $\Delta P^{*}$, in which galloping detonations occur is relatively small and indeed cannot be distinguished within experimental variations. Nevertheless, from Fig. 5, some minor trends might still be observed. For the smaller diameter tubes (i.e., $D=1.5 \mathrm{~mm}$ and $3.2 \mathrm{~mm}$ ), $L / D$ is of the order of 350 for $\mathrm{CH}_{4}+2 \mathrm{O}_{2}$ and $\mathrm{C}_{3} \mathrm{H}_{8}+5 \mathrm{O}_{2}$ while $L / D$ is of the order of 450 for $\mathrm{C}_{2} \mathrm{H}_{2}+5 \mathrm{~N}_{2} \mathrm{O}$ which has a relatively lower degree of instability among the three tested unstable mixtures. Beside, as the tube diameter increases, $L / D$ decreases and for $D=12.7 \mathrm{~mm}, L / D$ is of the order of 250 for all the three mixtures.

A collection of $L / D$ of galloping detonations from all previous studies together with the present results is illustrated in Fig. 6 where $L / D$ is plotted against initial pressure $P_{\mathrm{o}}$. Overall, the data agrees qualitatively the minor trends as those observed in Fig. 5 in the above discussion. Ignoring the fluctuations it can be concluded that $L / D$ on average is of the order of 350 for different mixtures and different tube diameters and geometries. Also the dependence of $L / D$ on initial pressure is negligible. Since $L / D \sim$ O[350] galloping detonations are cyclic phenomena 
with very long wavelength and for such long distance of propagation, galloping detonations are fairly reproducible. Note that the wavelength of hundreds of tube diameters is at least two orders of magnitude larger than the standard characteristic length scale of the detonation front, e.g., cell size.

It is also of interest to examine the amplitudes of the velocity fluctuation in a galloping cycle. Figure 7 shows the upper and lower values of the velocity in a galloping cycle for the three unstable mixtures. Each plot in Fig. 7 is divided into three (shaded) regions showing the variation of the maximum peak, average and minimum peak of the galloping cycle (s). The initial pressure is varied over the range where galloping detonations are observed. From these plots, one can see that with a large shaded band the upper velocity values show more fluctuations than the lower values. However, the general trend is that the upper value of the velocity is above the CJ velocity (i.e., $V_{\mathrm{CJ}}$ to $1.5 V_{\mathrm{CJ}}$ ) indicating that the detonation is overdriven at the start of the galloping cycle. The lower values of the velocity are between $0.3 V_{\mathrm{CJ}}$ to $0.65 V_{\mathrm{CJ}}$ and hence, in general, the lower value of the galloping cycle shows more consistent trend with less variation across different initial pressures or a result with multiple galloping cycles. The average velocity values of the galloping detonation are also computed from the local velocity measurement. These values are found to be approximately $0.9 V_{\mathrm{CJ}}, 0.79 V_{\mathrm{CJ}}$ and $0.78 V_{\mathrm{CJ}}$ for $\mathrm{CH}_{4}+2 \mathrm{O}_{2}, \mathrm{C}_{3} \mathrm{H}_{8}+5 \mathrm{O}_{2}$ and $\mathrm{C}_{2} \mathrm{H}_{2}+5 \mathrm{~N}_{2} \mathrm{O}$, respectively. These results agree with those reported in the literature (e.g., $[2,3$, 28]) that there is still a velocity deficit in the average velocity of the galloping detonation. The present results appear to be slight higher than those found in $[2,3,28]$ (i.e., $\sim 0.6 V_{\mathrm{CJ}}$ ). A possible reason for such discrepancy can be due to the velocity measurement used in the present study which has limited resolution and is not obtained continuously. 


\subsection{Effect of instability}

The general feature of a galloping detonation cycle is a long, low velocity phase where the wave propagates at about $0.4 V_{\mathrm{CJ}}$. At the end of the low velocity phase, the wave accelerates rapidly to an overdriven detonation velocity of about $1.2 V_{\mathrm{CJ}}$. Although the acceleration is relatively rapid, nevertheless, the acceleration phase occurs over few tens of tube diameter (e.g., $\sim 50 D$ ). The detonation does not remain in the overdriven state, and decay immediately to the sub-CJ low velocity phase to begin another galloping cycle. Figure 8a illustrate a typically galloping cycle in $\mathrm{C}_{3} \mathrm{H}_{8}+5 \mathrm{O}_{2}$ in a $D=12.7 \mathrm{~mm}$ diameter tube. These experiments are super-imposed to demonstrate the reproducibility of the galloping cycle. Smoked foil record [29] shows the decay of a multi-headed detonation to a single headed spin and eventually no cellular structure is observed in the low velocity phase of the cycle. The acceleration phase thus also relies on a rapid development of cellular structure to a fine multi-headed overdriven detonation at the end of the process.

The key propagation mechanism of galloping detonations is the ability to develop cells via instability in the shock-reaction zone complex of the low velocity phase. In a smooth walled tube instability develops from infinitesimal fluctuations. However, if finite perturbations are introduced via wall roughness, then the acceleration phase can be triggered and the growth of instability more rapid. To illustrate the effect of wall roughness, a short length of wire spiral (with 1-mm wire diameter, 10-mm pitch and 5 turns of the spiral) is introduced with the 12.7-mm diameter tube at the beginning of the low velocity phase of the galloping cycle, see Fig. 9. In addition, another section of polycarbonate tube was added to observe a whole cycle of galloping detonation after the perturbation and hence, total length of test section tube in this case is of about $5,000 \mathrm{~mm}$. The finite perturbations introduced artificially by the spiral triggered the 
rapid development of instability leading to the rapid acceleration to the overdriven state. Subsequently, the overdriven detonation decays immediately, and the usual galloping cycle follows in the remaining section of the tube. This is illustrated in Fig. $8 \mathrm{~b}$ in the $\mathrm{C}_{3} \mathrm{H}_{8}+5 \mathrm{O}_{2}$ mixture in the $12.7-\mathrm{mm}$ diameter tube. The results of two experiments are superimposed to illustrate the reproducibility of the phenomena. Similar behaviors are also observed for the other two unstable mixtures of $\mathrm{CH}_{4}+2 \mathrm{O}_{2}, \mathrm{C}_{2} \mathrm{H}_{2}+5 \mathrm{~N}_{2} \mathrm{O}$, as shown in Fig. 10 and Fig. 11 for comparison. Overall, the results from these experiments indicate that the instability caused by the

perturbation contributes to the onset of galloping detonations. The results also suggest why galloping detonations are much more readily obtained in unstable mixtures where the growth of instabilities can occur more readily.

\section{Conclusions}

This paper analyzes results for galloping detonations, previously published in [29] and additionally obtained in this study, in a variety of hydrocarbon fuel mixtures and diameter tubes. A summary of these results confirms that for stable mixtures, galloping detonation is not observed in all tested tubes. In contrast, for unstable mixtures, more than one cycle of galloping detonation is observed in small diameter tubes $(D=1.5,3.2$ and $12.7 \mathrm{~mm})$. The latter may suggest that strong reaction sensitivity or instability of the combustible mixtures is one of the key factors for galloping detonations. Experimentally for the case with the 50.8-mm diameter tube, detonations fail completely after short propagation distances upon entering the test section even for unstable mixtures. Its absence in large tubes implies that the transverse length scale (tube diameter) affects the galloping cycle. Alternatively, the range of initial pressures within which galloping detonations are observed is also found to decrease rapidly with tube diameter. The 
general trend is that for large enough diameter tubes, $\Delta P^{*} \rightarrow 0$ and no galloping detonations could be observed.

A collection of existing data indicates that the wave length of a galloping cycle, within experimental variation, is on average about $350 D$. Apart from the possibility of experimental variations, there appears some minor trend that the wavelength becomes smaller in larger tube diameter (i.e. $D \geq 12.7 \mathrm{~mm}$ ) or increases with increasing degree of detonation stability of the explosive mixture. The amplitude of the galloping cycle is also investigated and the upper velocity values show more fluctuation than the lower values. The upper and lower values of the velocity in the galloping cycle at different conditions range from $V_{\mathrm{CJ}}$ to $1.5 V_{\mathrm{CJ}}$ and $0.3 V_{\mathrm{CJ}}$ to $0.65 V_{\mathrm{CJ}}$, respectively. A velocity deficit is still presented in the averaged velocity of galloping detonation at different conditions which ranges from $0.75 V_{\mathrm{CJ}}$ to $0.9 V_{\mathrm{CJ}}$. To elucidate the effect of instability on the onset of galloping detonation, artificial perturbation generated by spiral is introduced in $12.7-\mathrm{mm}$ diameter tube. It is found that galloping detonation is re-initiated abruptly after passing the spiral, and another cycle of galloping detonation is formed in the remaining part of the tube. The results therefore support the fact that the ability to generate perturbations plays an important role in the onset of galloping detonations.

\section{Acknowledgement}

This work is supported by the Natural Sciences and Engineering Research Council of Canada (NSERC). The authors thank Dr. C.B. Kiyanda for his comments and proof-reading of this paper. 


\section{References}

[1] J.H.S. Lee, The Detonation Phenomenon, Cambridge University Press, New York, 2008.

[2] J.J. Lee, G. Dupré, R. Knystautas, J.H.S. Lee, Shock Waves 5 (1995) 175-181.

[3] F. Haloua, M. Brouillette, V. Lienhart, G. Dupré, Combust. Flame 122 (2000) 422-438.

[4] S.I. Jackson, B.J. Lee, W. Huang, F. Pintgen, J. Karnesky, Z. Liang, J.E. Shepherd, In: Proc. Proc. 22 ${ }^{\text {nd }}$ Int. Colloq. Dynamics Expl. Reac. Sys, Minsk, Belarus (2009).

[5] A. Camargo, H.D. Ng, J. Chao, J.H.S. Lee, Shock Waves 20(6) (2010) 499-508.

[6] A.J. Mooradian, W.E. Gordon, J. Chem. Phys. 19 (1951) 1166-1172.

[7] R.E. Duff, H.T. Knight, H.R. Wright, J. Chem. Phys. 22 (1954) 1618-1619.

[8] N. Manson, C. Brochet, J. Brossard, Y. Pujol, Proc. Combust. Inst. 9 (1963) 461-469.

[9] J.-P. Saint-Cloud, C. Guerraud, C. Brochet, N. Manson, Astronaut. Acta 17 (1972) 487-498.

[10] D.H. Edwards, J.M. Morgan, J. Phys. D: Appl. Phys. 10 (1977) 2377-2387.

[11] I.O. Moen, M. Donato, R. Knystautas, J.H.S. Lee, Proc. Combust. Inst. 18 (1981) $1615-1622$.

[12] G. Dupré, R. Knystautas, J.H.S. Lee, Prog. Astronaut. Aeronaut. 106 (1986) 244-259.

[13] A.A. Vasil'ev, Combust. Expl. Shock Waves 23(3) (1987) 358-364.

[14] K. Ishii, H. Gronig, Shock Waves 8 (1998) 55-61.

[15] V.I. Manzhalei, Combust. Expl. Shock Waves 35(3) (1999) 296-302.

[16] A.A. Vasil'ev, Shock Waves 18 (2008) 245-253.

[17] M.H. Wu, C.H. Wang, Proc. Combust. Inst. 33 (2011) 2287-2293.

[18] V.Y. Ul'yanitskii, Combust. Expl. Shock Waves 17(1) (1981) 93-97.

[19] S.M. Aksamentov, V.I. Manzhaley, V.V. Mitrofanov, Prog. Astronaut. Aeronaut. 153 (1992) $112-131$.

[20] N. Tsuboi, Y. Morii, A.K. Hayashi, Proc. Combust. Inst. 34 (2013) 1999-2007.

[21] S. Kitano, M. Fukao, A. Susa, N. Tsuboi, A.K. Hayashi, M. Koshi, Proc. Combust. Inst. 32 (2009) 2355-2362. 
[22] J. Chao, H.D. Ng, J.H.S. Lee, Proc. Combust. Inst. 32 (2009) 2349-2354.

[23] J. Fischer, C. Liebner, H. Hieronymus, E. Klemm, Chem. Eng. Sci. 64 (2009) 2951-2956.

[24] K. Ishii, M. Monwar, Proc. Combust. Inst. 33 (2011) 2359-2366.

[25] J.H.S. Lee, A. Jesuthasan, H.D. Ng, Proc. Combust. Inst. 34(2) (2013) 1957-1963.

[26] K. Sadahira, Y. Kitawaki, T. Inaba, A. Susa, K. Matsuoka, T. Johzaki, T. Endo, In: Proc. $24^{\text {th }}$ Int. Colloq. Dynamics Expl. Reac. Sys., Taipei, Taiwan (2013).

[27] Y. Gao, H.D. Ng, J.H.S. Lee, Shock Waves 24(4) (2014) 447-454.

[28] A. Susa, S. Hasegawa, H. Yokoyama, T. Endo, Y. Ogawa, Y. Morii, N. Tsuboi, In: Proc. $23^{\text {th }}$ Int. Colloq. Dynamics Expl. Reac. Sys., Irvine, USA (2011).

[29] Y. Gao, J.H.S. Lee, H.D. Ng, Combust. Flame 161(11) (2014) 2982-2990.

[30] M.I. Radulescu, H.D. Ng, J.H.S. Lee, B. Varatharajan, Proc. Combust. Inst. 29 (2002) $2825-2831$.

[31] H.D. Ng, F. Zhang, Detonation Instability. In: Shock Wave Science and Technology Library. Detonation Dynamics, Vol. 6 (ed. Zhang F.) (2012) pp. 107-212, Springer, Berlin.

[32] B.J. Mcbride, S. Gordon. Computer Program for Calculation of Complex Chemical Equilibrium Compositions and Applications. RP-1311, NASA Reference Publication, Cleveland (1996).

[33] M. Short, J.J. Quirk, J. Fluid Mech. 339 (1997) 89-119.

[34] Y.J. Zhu, J. Chao, J.H.S. Lee, Proc. Combust. Inst. 31(1) (2007) 2455-2462.

[35] R.S .Chue, J.H. Lee, F. Zhang, Shock Waves 5 (1995) 159-167. 


\section{Table captions}

Table 1. Summary of published results of galloping detonation in the literature

\begin{tabular}{|c|c|c|c|c|}
\hline Mixture & $\begin{array}{c}\text { Tube or } \\
\text { channel size } \\
(\mathrm{mm})\end{array}$ & $\begin{array}{c}\text { Tube or } \\
\text { channel length } \\
(\mathrm{mm})\end{array}$ & $\begin{array}{l}l / D \text { or } \\
l / D_{H}{ }^{*}\end{array}$ & $\begin{array}{c}\text { Galloping } \\
\text { detonation }\end{array}$ \\
\hline $\mathrm{C}_{2} \mathrm{H}_{4}+(4.3 \sim 8.6) \mathrm{O}_{2}^{[17]}$ & 0.5 & 750 & 1500 & Yes \\
\hline $\mathrm{C}_{2} \mathrm{H}_{2}+2.5 \mathrm{O}_{2}^{[15]}$ & 0.6 & 300 & 500 & Yes \\
\hline $\mathrm{C}_{2} \mathrm{H}_{2}+5 \mathrm{O}_{2}^{[15]}$ & 1 & 1300 & 1300 & Yes \\
\hline $\mathrm{C}_{2} \mathrm{H}_{2}+9.5 \mathrm{O}_{2}^{[15]}$ & 1 & 1300 & 1300 & Yes \\
\hline $\mathrm{CH}_{4}+2 \mathrm{O}_{2}^{[28]}$ & 3 & 5000 & 1667 & Yes \\
\hline $\mathrm{CH}_{4}+2 \mathrm{O}_{2}^{[28]}$ & 4 & 5000 & 1250 & Yes \\
\hline $\mathrm{C}_{3} \mathrm{H}_{8}+5 \mathrm{O}_{2}^{[4]}$ & 4.8 & 50000 & 10416 & Yes \\
\hline $2 \mathrm{H}_{2}+\mathrm{O}_{2}+3.6 \mathrm{~N}_{2}^{[20]}$ & 5 & 4000 & 800 & Yes \\
\hline $\mathrm{CH}_{4}+2 \mathrm{O}_{2}{ }^{[28]}$ & 6 & 5000 & 833 & Yes \\
\hline $\mathrm{CH}_{4}+2 \mathrm{O}_{2}^{[5]}$ & 6.3 & 3000 & 476 & Yes \\
\hline $\mathrm{CH}_{4}+2 \mathrm{O}_{2}^{[28]}$ & 9 & 5000 & 555 & Yes \\
\hline $\mathrm{CH}_{4}+2 \mathrm{O}_{2}^{[5]}$ & 9.5 & 3000 & 315 & Yes \\
\hline $\mathrm{CH}_{4}+2 \mathrm{O}_{2}^{[19]}$ & 12.7 & 8000 & 630 & Yes \\
\hline $2 \mathrm{H}_{2}+\mathrm{O}_{2}^{[19]}$ & 12.7 & 8000 & 630 & Yes \\
\hline $\mathrm{CH}_{4}+2 \mathrm{O}_{2}^{[18]}$ & 12.8 & 7000 & 546 & Yes \\
\hline $\mathrm{C}_{3} \mathrm{H}_{8}+5 \mathrm{O}_{2}+7.9 \mathrm{Ar}^{[10]}$ & $23 \times 10$ & 30000 & 2158 & Yes \\
\hline $\mathrm{C}_{3} \mathrm{H}_{8}+5 \mathrm{O}_{2}+19.8 \mathrm{~N}_{2}^{[10]}$ & $23 \times 10$ & 30000 & 2158 & Yes \\
\hline $\mathrm{C}_{3} \mathrm{H}_{8}+5 \mathrm{O}_{2}+9.9 \mathrm{~N}_{2}^{[10]}$ & $23 \times 10$ & 30000 & 2158 & Yes \\
\hline $\mathrm{C}_{3} \mathrm{H}_{8}+5 \mathrm{O}_{2}+7.9 \mathrm{~N}_{2}^{[10]}$ & $23 \times 10$ & 30000 & 2158 & Yes \\
\hline $\mathrm{H}_{2}+1.4 \mathrm{O}_{2}$ & $23 \times 10$ & 30000 & 2158 & Yes \\
\hline $\mathrm{C}_{3} \mathrm{H}_{8}+5 \mathrm{O}_{2}+11.6 \mathrm{~N}_{2}{ }^{[8]}$ & 20 & 35000 & 1750 & Yes \\
\hline $\mathrm{C}_{3} \mathrm{H}_{8}+5 \mathrm{O}_{2}+18 \mathrm{~N}_{2}^{[8]}$ & 20 & 35000 & 1750 & Yes \\
\hline $\mathrm{H}_{2}+\mathrm{O}_{2}+3.7 \mathrm{~N}_{2}^{[6]}$ & 20 & 10000 & 500 & Yes \\
\hline $\mathrm{C}_{2} \mathrm{H}_{4}+3 \mathrm{O}_{2}^{[2]}$ & 38 & 10000 & 263 & Yes \\
\hline $\mathrm{C}_{2} \mathrm{H}_{6}+3.5 \mathrm{O}_{2}^{[2]}$ & 38 & 10000 & 263 & Yes \\
\hline $\mathrm{C}_{3} \mathrm{H}_{8}+5 \mathrm{O}_{2}^{[2]}$ & 38 & 10000 & 263 & Yes \\
\hline $\mathrm{C}_{3} \mathrm{H}_{8}+5 \mathrm{O}_{2}+6 \mathrm{~N}_{2}^{[2]}$ & 38 & 10000 & 263 & Yes \\
\hline $\mathrm{C}_{3} \mathrm{H}_{8}+5 \mathrm{O}_{2}+6 \mathrm{Ar}^{[2]}$ & 38 & 10000 & 263 & No \\
\hline $\mathrm{C}_{2} \mathrm{H}_{2}+2.5 \mathrm{O}_{2}+10.5 \mathrm{Ar}^{[2]}$ & 38 & 10000 & 263 & No \\
\hline $\mathrm{C}_{2} \mathrm{H}_{2}+2.5 \mathrm{O}_{2}+9.3 \mathrm{~N}_{2}^{[2]}$ & 38 & 10000 & 263 & No \\
\hline $\mathrm{C}_{2} \mathrm{H}_{2}+5 \mathrm{~N}_{2} \mathrm{O}+6 \mathrm{Ar}^{[2]}$ & 38 & 10000 & 263 & No \\
\hline $\mathrm{C}_{3} \mathrm{H}_{8}+5 \mathrm{O}_{2}+6 \mathrm{Ar}^{[3]}$ & 38 & 24500 & 644 & Yes \\
\hline $\mathrm{C}_{3} \mathrm{H}_{8}+5 \mathrm{O}_{2}+9 \mathrm{Ar}^{[3]}$ & 38 & 24500 & 644 & Yes \\
\hline $\mathrm{C}_{3} \mathrm{H}_{8}+5 \mathrm{O}_{2}+14 \mathrm{Ar}^{[3]}$ & 38 & 24500 & 644 & No \\
\hline $\mathrm{C}_{3} \mathrm{H}_{8}+5 \mathrm{O}_{2}+6 \mathrm{He}^{[3]}$ & 38 & 24500 & 644 & Yes \\
\hline $\mathrm{C}_{3} \mathrm{H}_{8}+5 \mathrm{O}_{2}+9 \mathrm{He}^{[3]}$ & 38 & 24500 & 644 & No \\
\hline $2 \mathrm{H}_{2}+\mathrm{O}_{2}^{[14]}$ & 45 & 14000 & 311 & Yes \\
\hline
\end{tabular}

* $D_{\mathrm{H}}$ denotes the corresponding hydraulic diameter

Table 1. 


\section{Figures captions}

Fig. 1. A schematic of the experimental apparatus

Fig. 2. Velocity measurement along the small diameter tube with $D=1.5 \mathrm{~mm}$

Fig. 3. Velocity results for mixtures a) $\mathrm{C}_{3} \mathrm{H}_{8}+5 \mathrm{O}_{2}$; b) $\mathrm{C}_{2} \mathrm{H}_{2}+5 \mathrm{~N}_{2} \mathrm{O}$; and c) $\mathrm{CH}_{4}+2 \mathrm{O}_{2}$ in the 50.8-mm diameter tube

Fig. 4. Mixture condition for the existence of galloping detonation. (The shaded rectangle represents an uncertain region where the result is limited by the tube length).

Fig. 5. Upper and lower pressure limits of galloping detonation as a function of tube diameter for a) $\mathrm{CH}_{4}+2 \mathrm{O}_{2}$; b) $\mathrm{C}_{3} \mathrm{H}_{8}+5 \mathrm{O}_{2}$; and c) $\mathrm{C}_{2} \mathrm{H}_{2}+5 \mathrm{~N}_{2} \mathrm{O}$ mixtures

Fig. 6. Wavelength of a galloping cycle

Fig. 7. Galloping wavelength as a function of initial pressure for a) $\mathrm{CH}_{4}+2 \mathrm{O}_{2}$; b) $\mathrm{C}_{3} \mathrm{H}_{8}+5 \mathrm{O}_{2}$; and c) $\mathrm{C}_{2} \mathrm{H}_{2}+5 \mathrm{~N}_{2} \mathrm{O}$ mixtures

Fig. 8. Comparison of galloping wavelength of various results

Fig. 9. Maximum, minimum and averaged value of galloping detonation for a) $\mathrm{CH}_{4}+2 \mathrm{O}_{2}$; b) $\mathrm{C}_{3} \mathrm{H}_{8}+5 \mathrm{O}_{2}$; and c) $\mathrm{C}_{2} \mathrm{H}_{2}+5 \mathrm{~N}_{2} \mathrm{O}$ mixtures

Fig. 10. Galloping detonation of the $\mathrm{C}_{3} \mathrm{H}_{8}+5 \mathrm{O}_{2}$ mixture, a) without spiral, b) with spiral. Different symbols at each plot represent repeat runs of the same condition.

Fig. 11. A Schematic of the spiral used to generate the perturbation

Fig. 12. Galloping detonation of the $\mathrm{CH}_{4}+2 \mathrm{O}_{2}$ mixture, a) without spiral, b) with spiral. Different symbols at each plot represent repeat runs of the same condition.

Fig. 13. Galloping detonation of the $\mathrm{C}_{2} \mathrm{H}_{2}+5 \mathrm{~N}_{2} \mathrm{O}$ mixture, a) without spiral, b) with spiral. Different symbols at each plot represent repeat runs of the same condition. 


\section{Figures}

Click here to download Figure: figures.doc

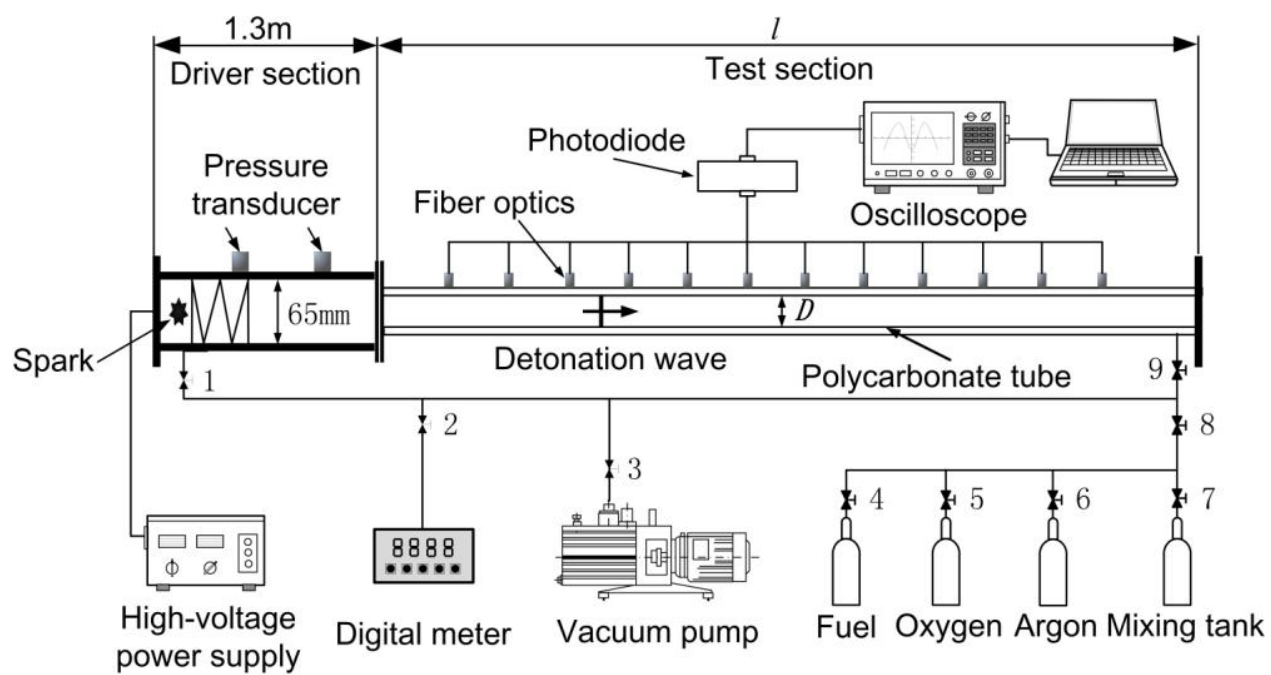

Fig. 1. 


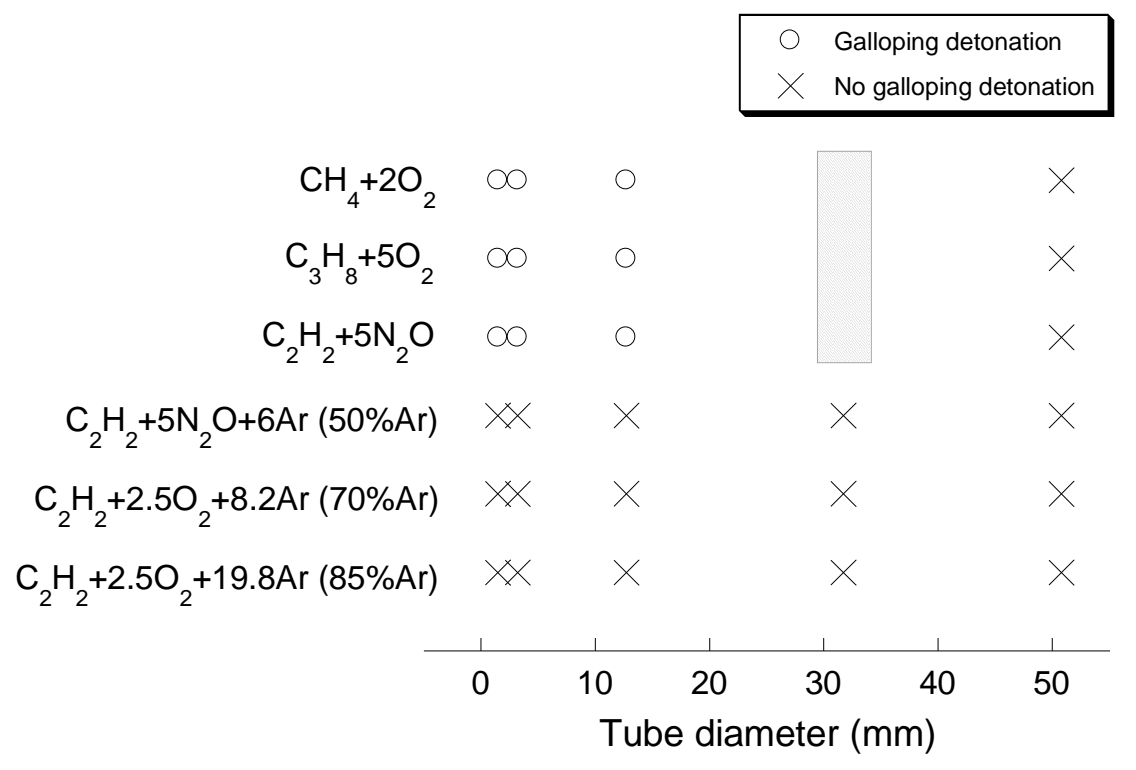

Fig. 2. 


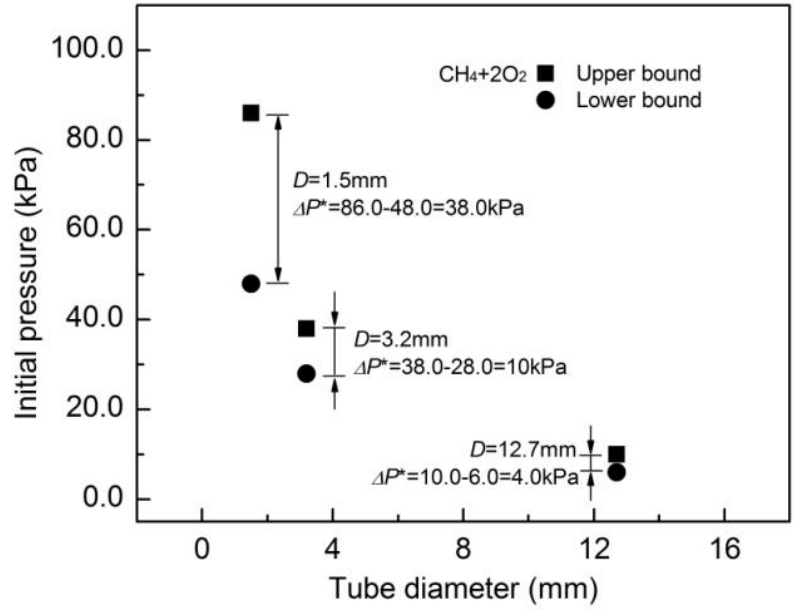

(a)

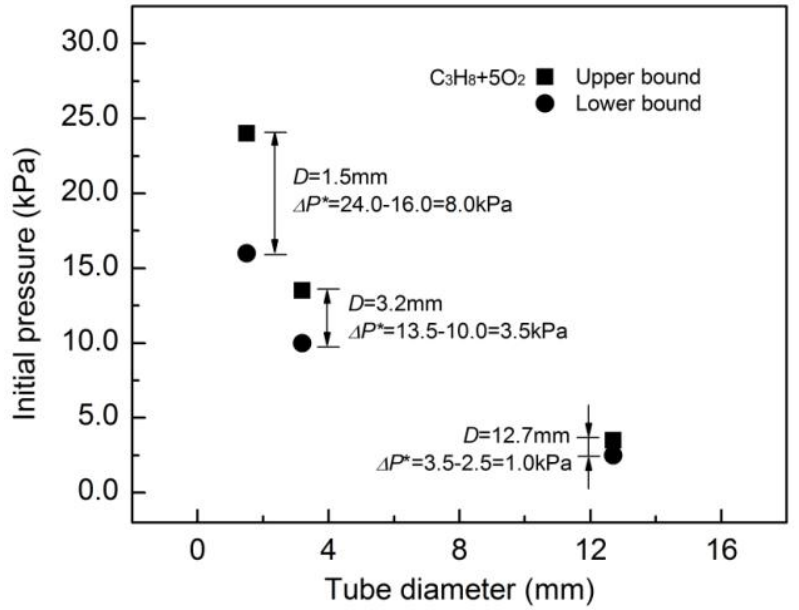

(b)

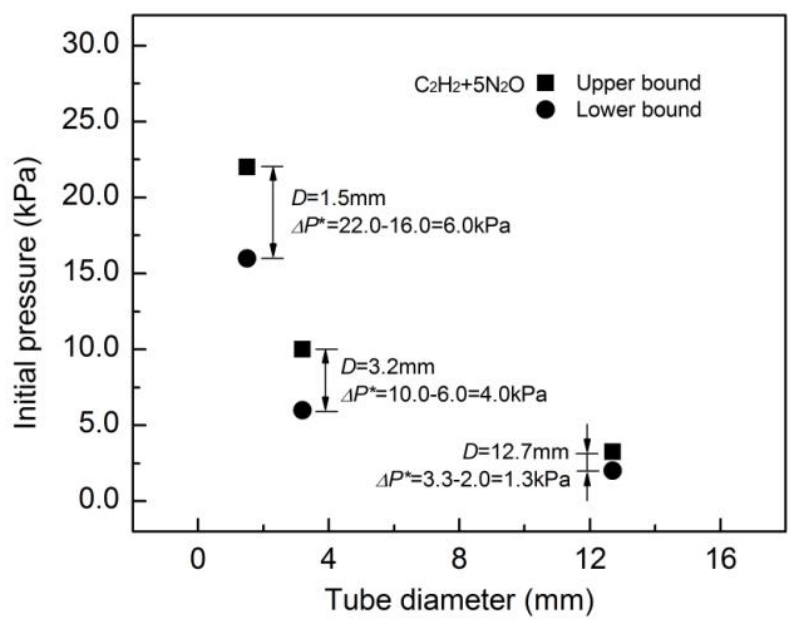

(c)

Fig. 3. 


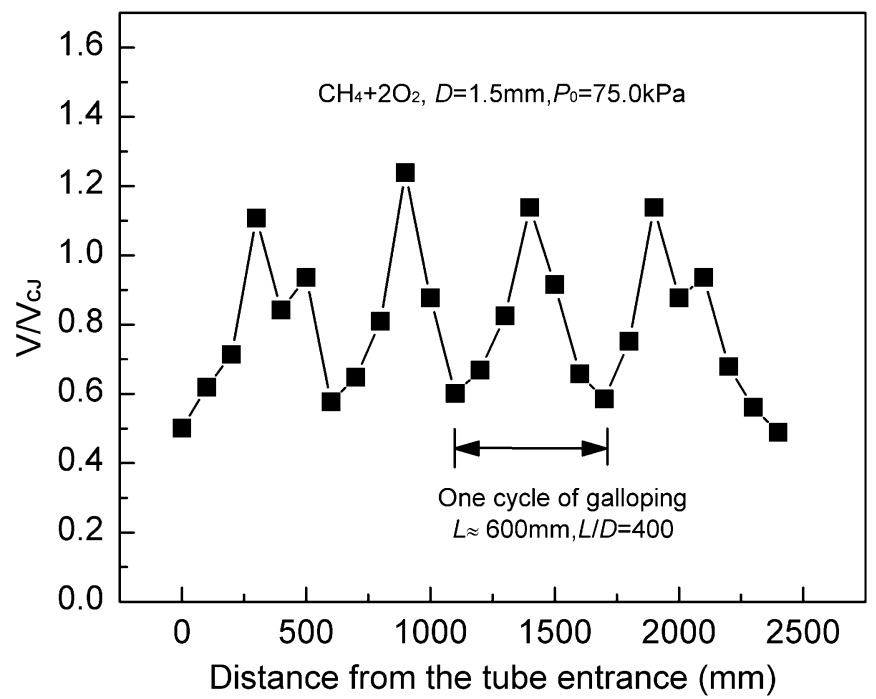

(a)

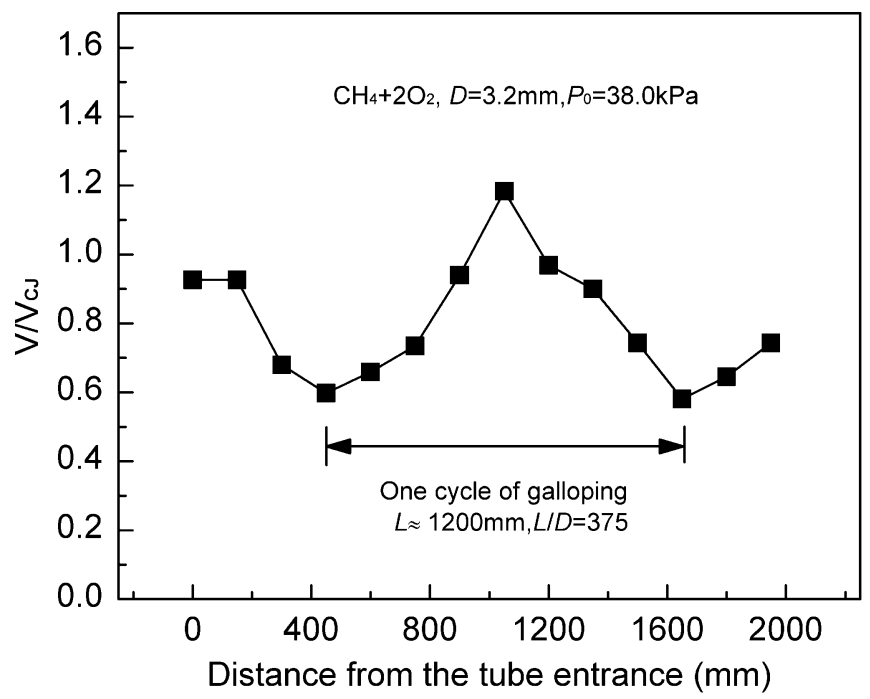

(b)

Fig. 4. 


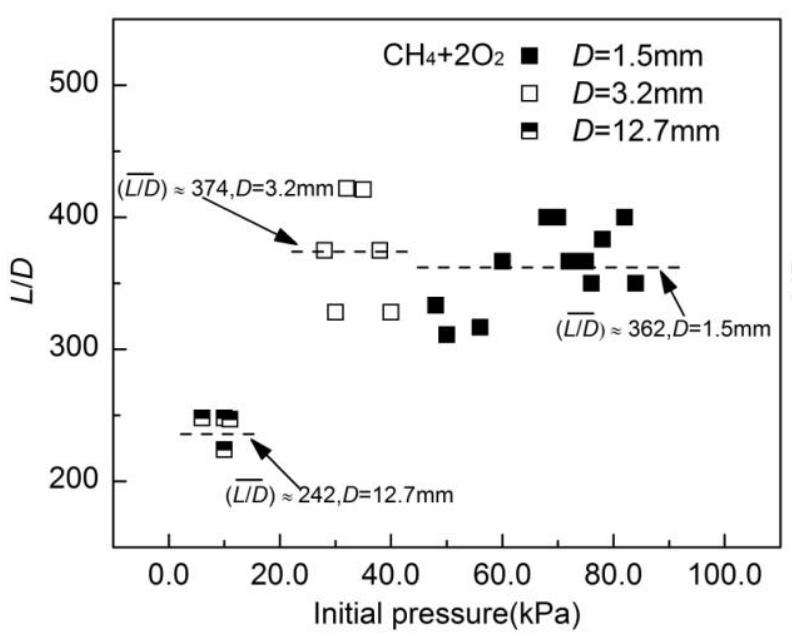

(a)

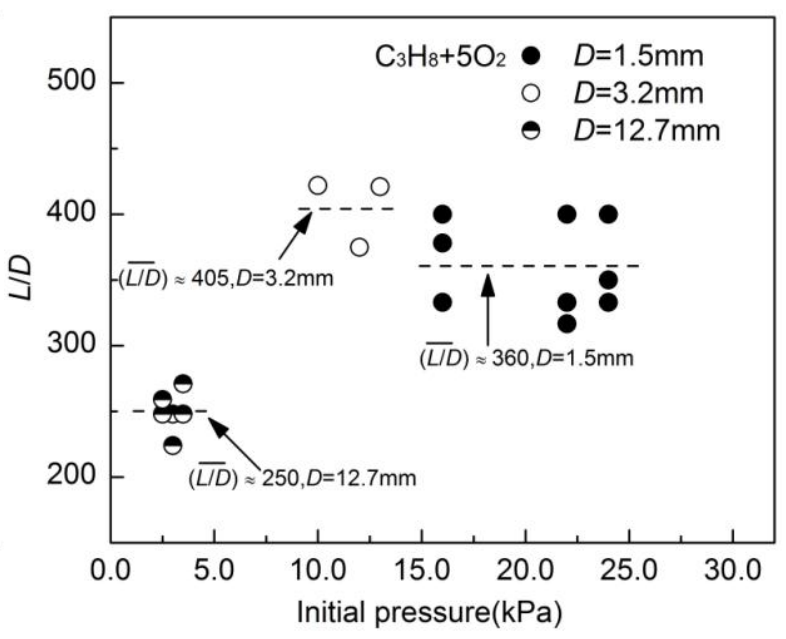

(b)

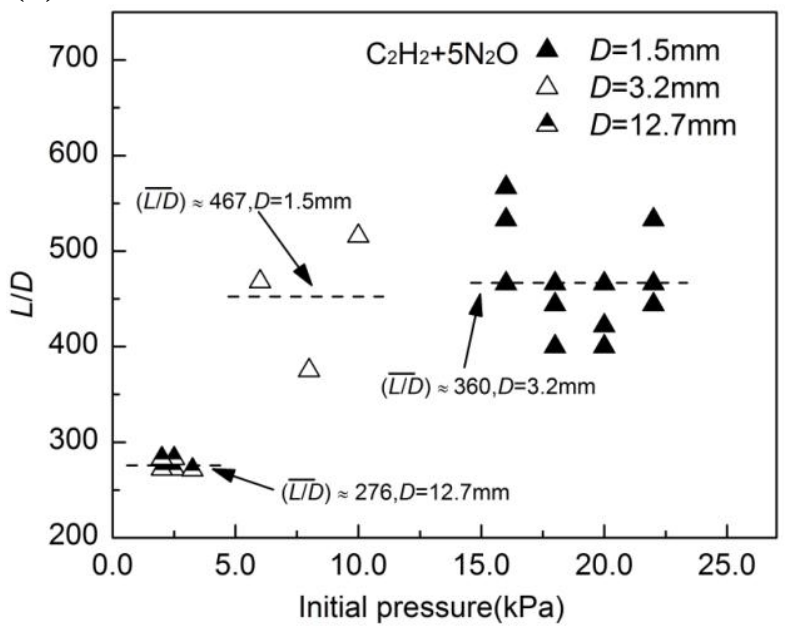

(c)

Fig. 5. 


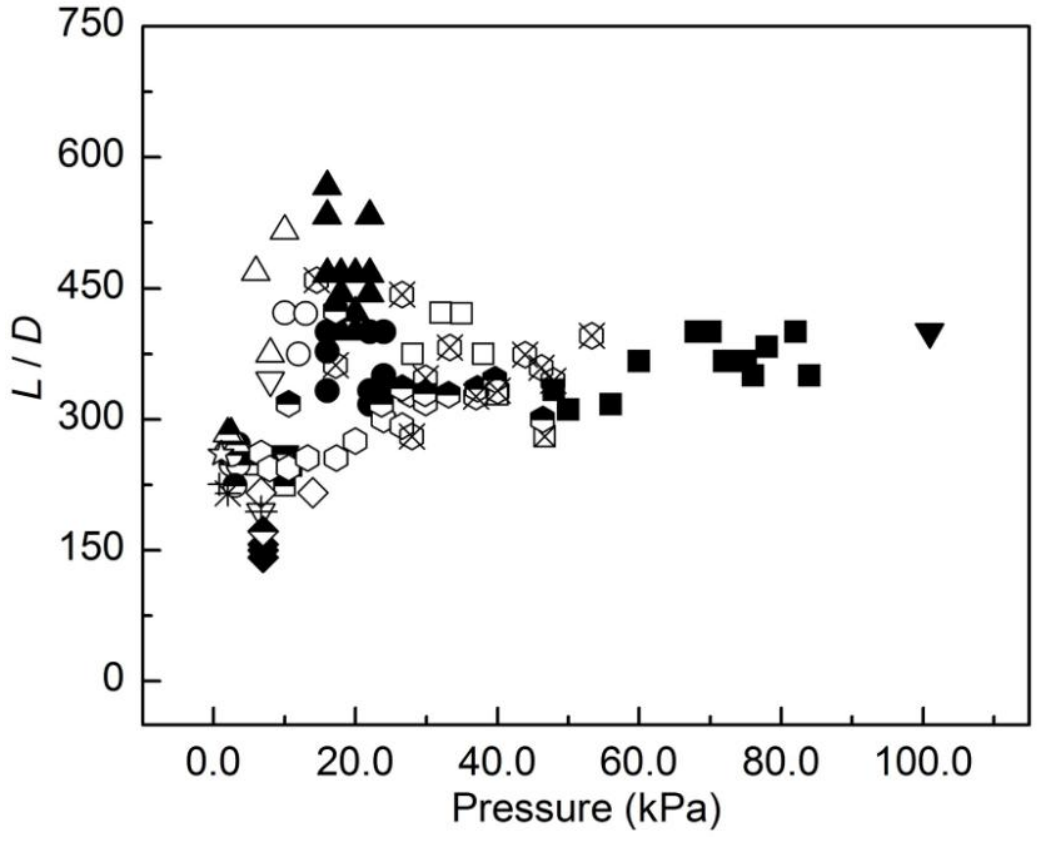

- $\mathrm{CH}_{4}+2 \mathrm{O}_{2}, D=1.5 \mathrm{~mm}$

$\mathrm{CH}_{4}+2 \mathrm{O}_{2}, D=3.2 \mathrm{~mm}$

- $\mathrm{CH}_{4}+2 \mathrm{O}_{2}, D=12.7 \mathrm{~mm}$ $\mathrm{C}_{3} \mathrm{H}_{8}+5 \mathrm{O}_{2}, D=1.5 \mathrm{~mm}$ $\mathrm{C}_{3} \mathrm{H}_{8}+5 \mathrm{O}_{2}, D=3.2 \mathrm{~mm}$ - $\mathrm{C}_{3} \mathrm{H}_{8}+5 \mathrm{O}_{2}, D=12.7 \mathrm{~mm}$ $\mathrm{C}_{2} \mathrm{H}_{2}+5 \mathrm{~N}_{2} \mathrm{O}, D=1.5 \mathrm{~mm}$

$\triangle \mathrm{C}_{2} \mathrm{H}_{2}+5 \mathrm{~N}_{2} \mathrm{O}, D=3.2 \mathrm{~mm}$

$\triangle \mathrm{C}_{2} \mathrm{H}_{2}+5 \mathrm{~N}_{2} \mathrm{O}, D=12.7 \mathrm{~mm}$

V $\mathrm{C}_{2} \mathrm{H}_{4}+8.6 \mathrm{O}_{2}, D=0.5 \mathrm{~mm}$ [17]

$\nabla \mathrm{C}_{3} \mathrm{H}_{8}+5 \mathrm{O}_{2}, \mathrm{D}=4.8 \mathrm{~mm} \mathrm{[4]}$

$2 \mathrm{H}_{2}+\mathrm{O}_{2}+3.6 \mathrm{~N}_{2}, D=5 \mathrm{~mm}$ [20]

$\mathrm{CH}_{4}+2 \mathrm{O}_{2}, D=12.7 \mathrm{~mm}$ [19]

$2 \mathrm{H}_{2}+\mathrm{O}_{2}, D=12.7 \mathrm{~mm}$ [19]

$8 \mathrm{CH}_{4}+2 \mathrm{O}_{2}, \mathrm{D}=12.7 \mathrm{~mm}$ [18]

$¥ \mathrm{C}_{3} \mathrm{H}_{8}+5 \mathrm{O}_{2}+7.9 \mathrm{Ar}, D=13.9 \mathrm{~mm}[10]$

$\triangle \mathrm{C}_{3} \mathrm{H}_{8}+5 \mathrm{O}_{2}+19.5 \mathrm{~N}_{2}, D=13.9 \mathrm{~mm}[10]$

$+\mathrm{C}_{3} \mathrm{H}_{8}+5 \mathrm{O}_{2}, D=38.4 \mathrm{~mm}[3]$

is $\mathrm{C}_{3} \mathrm{H}_{8}+5 \mathrm{O}_{2}, D=38.4 \mathrm{~mm}$ [2]

米 $2 \mathrm{H}_{2}+\mathrm{O}_{2}, D=45 \mathrm{~mm}$ [14]

$\mathrm{CH}_{4}+2 \mathrm{O}_{2}, D=6 \mathrm{~mm}$ [28]

$\mathrm{CH}_{4}+2 \mathrm{O}_{2}, D=4 \mathrm{~mm}[28]$

冈 $\mathrm{CH}_{4}+2 \mathrm{O}_{2}, D=3 \mathrm{~mm}[28]$

Fig. 6. 


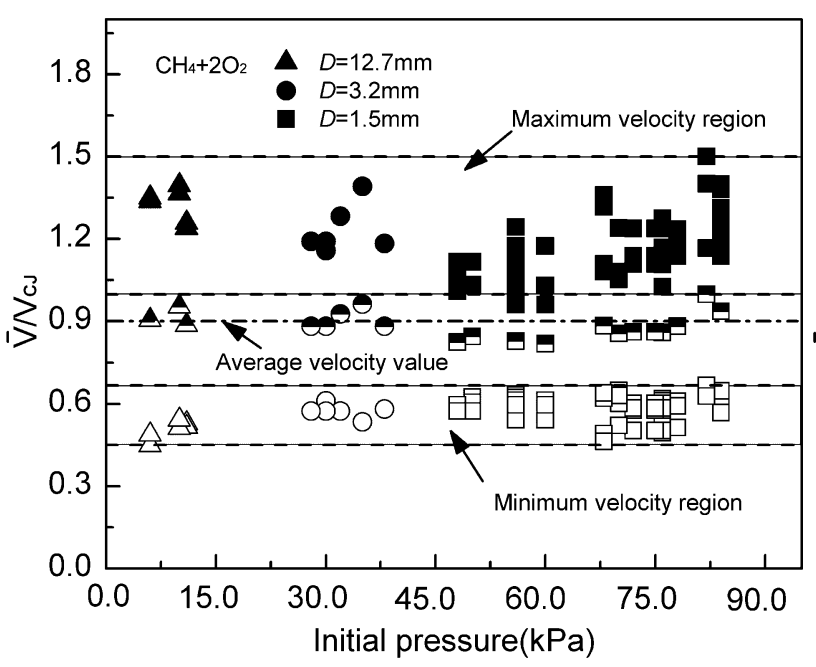

(a)

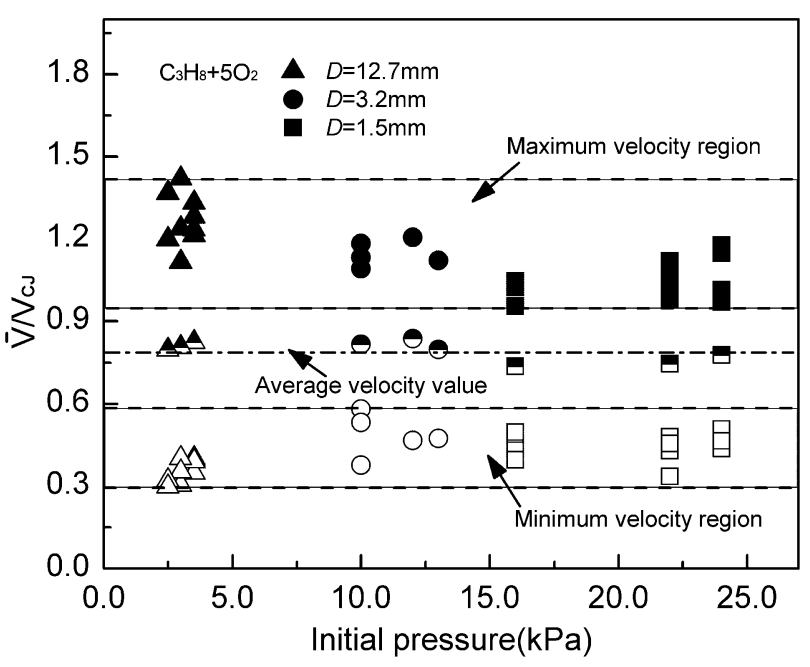

(b)

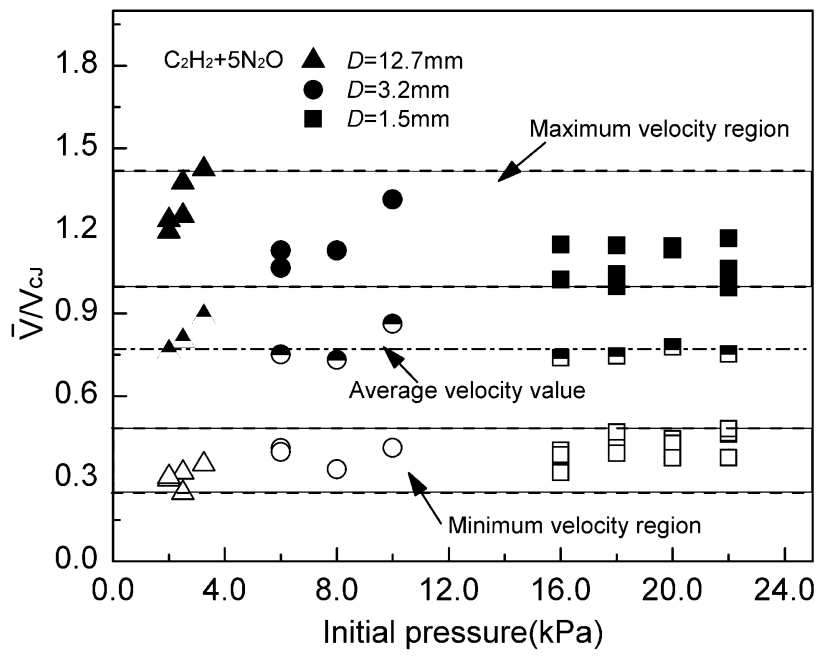

(c)

Fig. 7. 


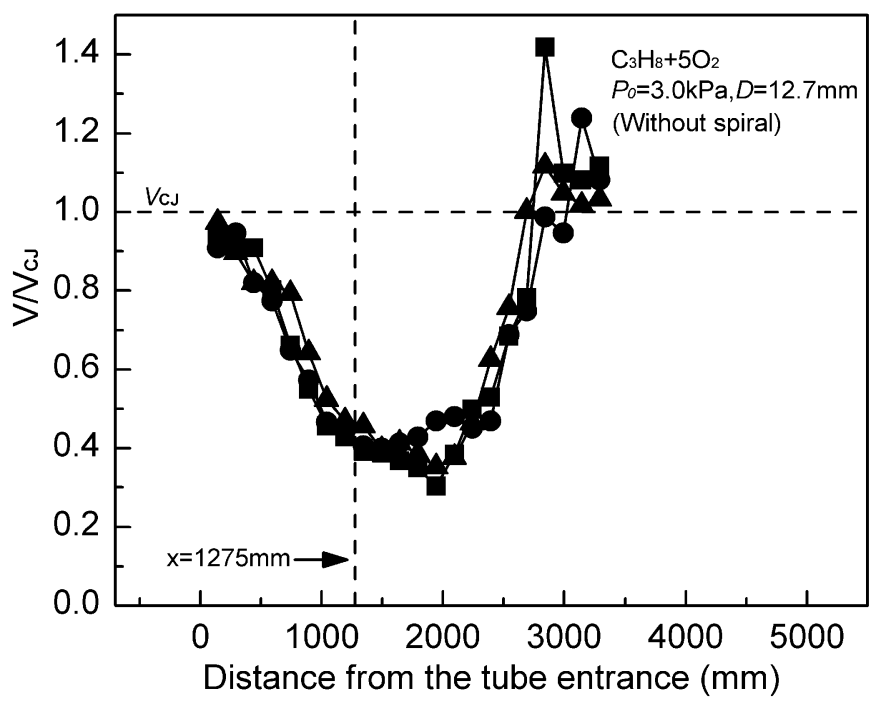

(a)

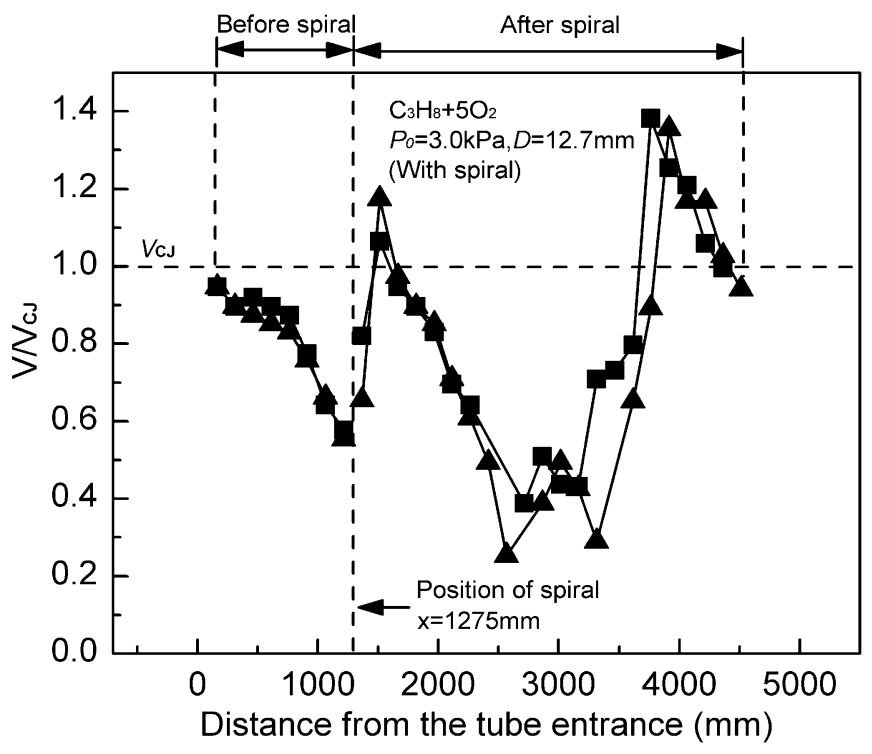

(b)

Fig. 8. 

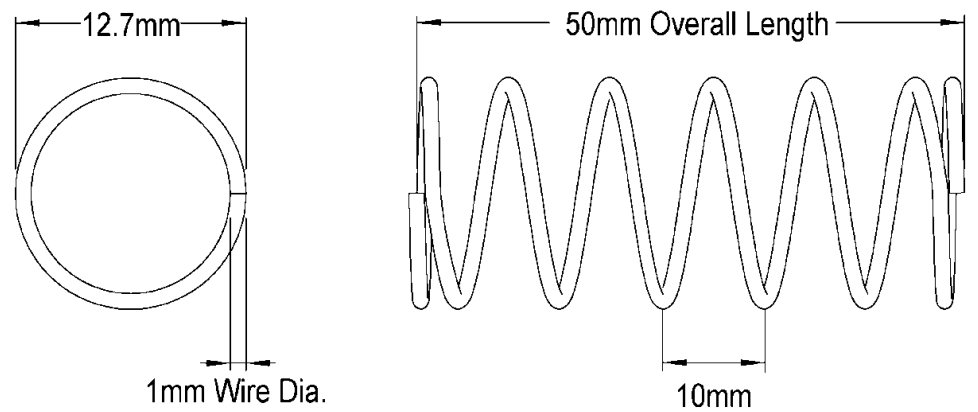

Fig. 9.

Page 9 of 11 


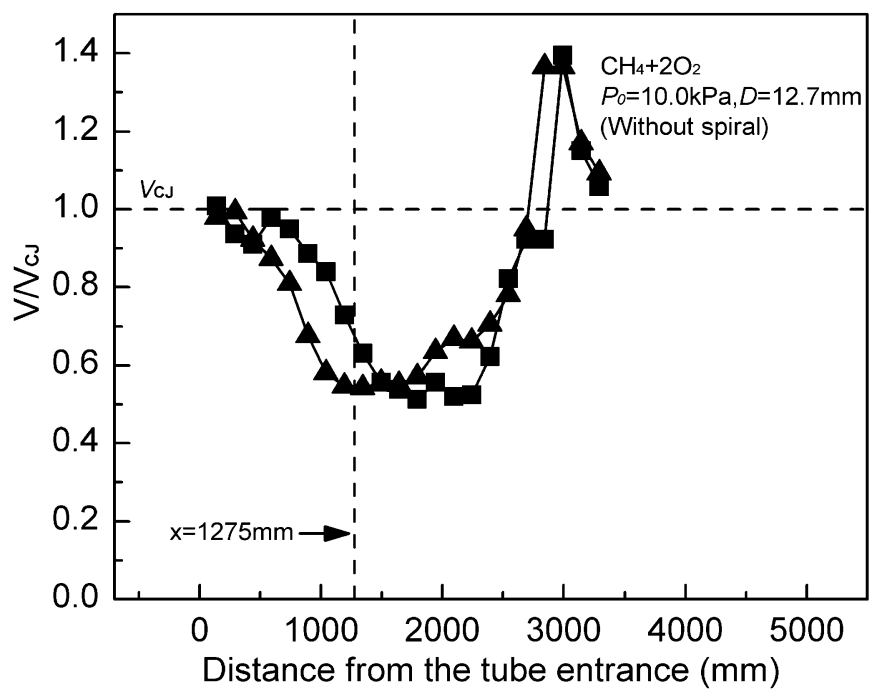

(a)

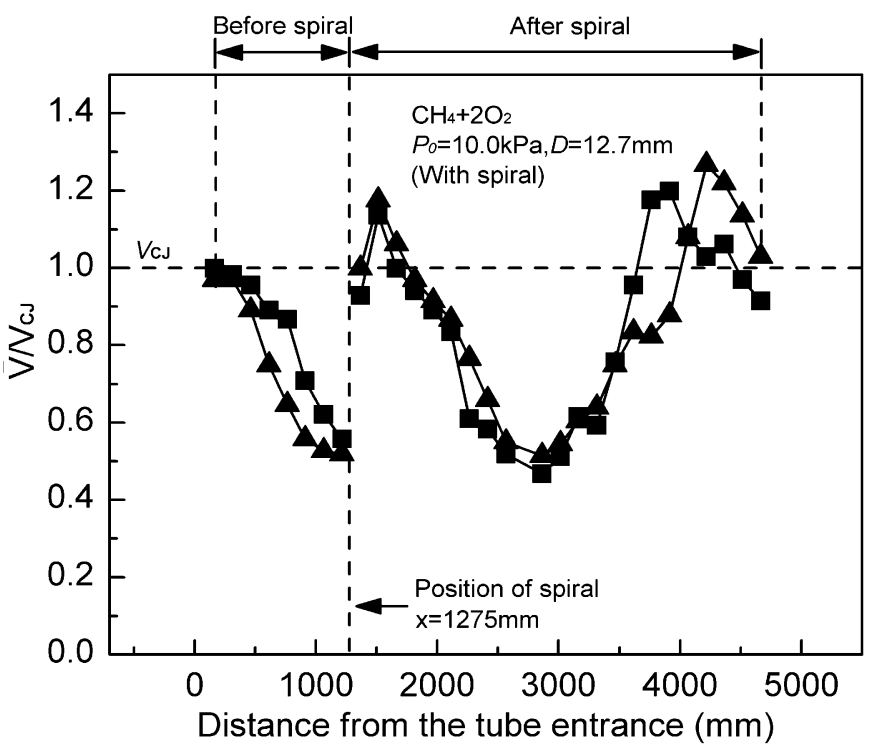

(b)

Fig. 10. 


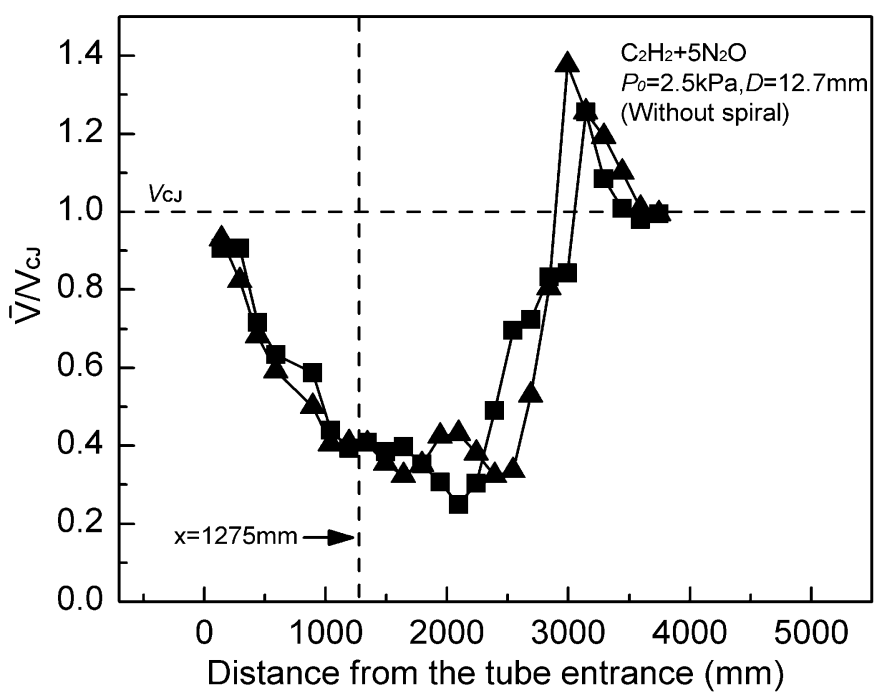

(a)

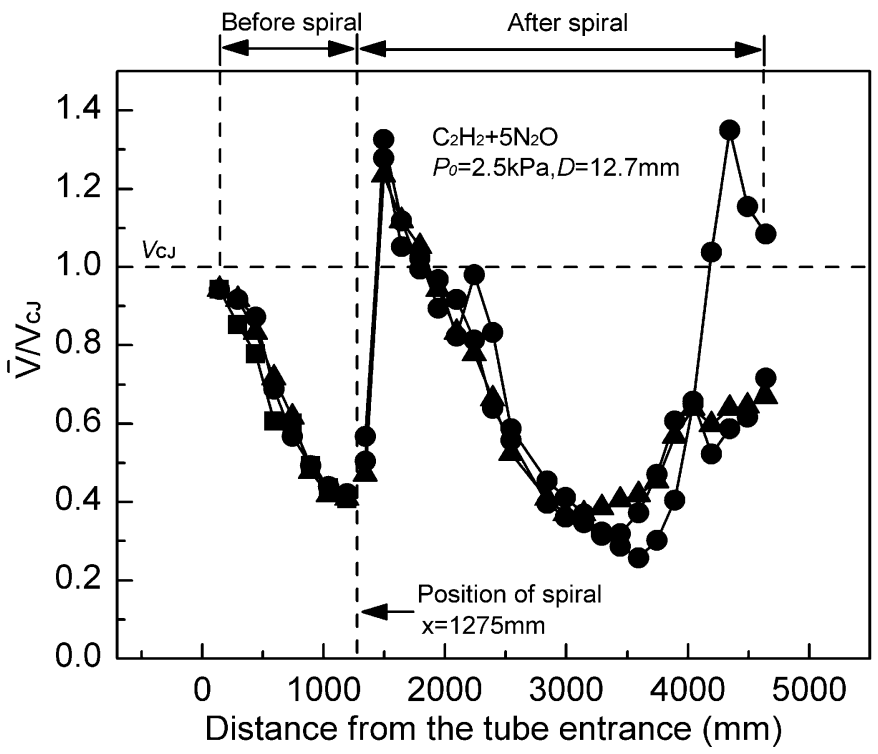

(b)

Fig. 11. 